\title{
The Synthesis of Citrovorum Factor by Leuconostoc mesenteroides $\mathbf{P} 60$
}

\author{
BY M. J. CROSS \\ Microbiology Unit, Department of Biochemistry, University of Oxford
}

(Received 28 January 1960)

\begin{abstract}
SUMMARY
When incubated with $p$-aminobenzoic acid, formate and glucose, suspensions of a variant strain of Leuconostoc mesenteroides strain $P 60$ formed two factors possessing folic acid activity. One of these factors behaved like rhizopterin in supporting the growth of Streptococcus faecalis strain $\mathbf{R}$ but not of Lactobacillus case $i$. The other, like leucovorin, supported the growth of Leuconostoc citrovorum. The synthesis of 'citrovorum factor' was enhanced 5- to 20-fold by the presence of $\mathrm{CO}_{2}$ in the gas phase. Sulphathiazole inhibited the synthesis of both factors, the inhibition being overcome competitively by $p$-aminobenzoic acid. Leucovorin was destroyed by suspensions of $L$. mesenteroides $\mathbf{P} 60$ in phosphate-buffered glucose. The diminution of activity for $L$. citrovorum (decrease of citrovorum factor) was decreased when the incubation was carried out in a $\mathrm{CO}_{2}$-enriched atmosphere. Ascorbic acid, which behaved similarly to $\mathrm{CO}_{2}$ in partially preventing inactivation of leucovorin by suspensions of $L$. mesenteroides $P 60$ variant strain, also increased the synthesis of citrovorum factor from formate and $p$-aminobenzoic acid and partially satisfied the requirement of the growing $L$. mesenteroides $\mathbf{P} 60$ for $\mathrm{CO}_{2}$.
\end{abstract}

\section{INTRODUCTION}

Carbon dioxide will replace serine for the growth of Leuconostoc mesenteroides P60 provided that glycine is present at relatively high concentration; yet, under these conditions, ${ }^{14} \mathrm{CO}_{2}$ is not incorporated into the serine synthesized (Cross, 1960). The growth of $L$. mesenteroides $\mathbf{P 6 0}$ also occurs in the absence of both serine and $\mathrm{CO}_{2}$, when the $p$-aminobenzoic acid in the medium is replaced by leucovorin (Lascelles, Cross \& Woods, 1954). This suggested that the group of reactions in which the intervention of $\mathrm{CO}_{2}$ is necessary might be those leading from $p$-aminobenzoic $(p-A B)$ acid to the final coenzyme form of folic acid. The present work provides evidence of the dependence of the ' $L$. citrovorum factor' (citrovorum factor) concentration in suspensions of a variant strain of $L$. mesenteroides $P 60$ upon the presence of carbon dioxide in the gas phase.

\section{METHODS}

Leuconostoc mesenteroides $\boldsymbol{P}$ 60. The two strains used were those used by Cross (1960). The variant strain was derived from $L$. mesenteroides P60 (Streptococcus equinis P60; ATCC 7881) by repeated subculture in the absence of added serine. The variant strain synthesizes serine more efficiently in growing cultures and in 
suspensions than does the parent strain. The media, conditions of growth and the method of assessment of growth were as described previously.

Suspensions of organisms deficient in $p$-aminobenzoic acid and in vitamin $\mathbf{B}_{6}$ were also obtained and incubated as previously described. The complete solution for the synthesis of citrovorum factor normally contained: glucose, $10^{-2} \mathrm{M}$; sodium formate, $10^{-2} \mathrm{M} ; p$-aminobenzoic acid, $10^{-5} \mathrm{M}$; phosphate buffer, $\mathrm{pH} 6 \cdot 9,1^{-1} \mathrm{M}$. In some experiments, in which the synthesis of serine and citrovorum factor were being observed concurrently, the reaction mixture (solution $D$ ) also contained: glycine, $2 \times 10^{-2} \mathrm{M}$ and pyridoxal, $10^{-6} \mathrm{M}$ (Cross, 1960). Modifications in particular experiments are noted in the text.

In experiments in which the organisms were incubated in $2 \times 10^{-2} \mathrm{M}$-glucose and $10^{-1} \mathrm{M}$-phosphate buffer ( $\mathrm{pH} \mathrm{6.9)}$ before testing their synthetic ability, the procedure was again exactly as previously described (Cross, 1960).

Microbiological assay of citrovorum factor. The preparation of material for the assay of citrovorum factor and the assay with Leuconostoc citrovorum (ATCC 8081) was carried out as described by Lascelles \& Woods (1952, 1954). Leucovorin was used as a standard and gave a dose-response curve similar to that of the sample under test (Fig. 1). The effective range of the assay was from 0.2 to $1.5 \mu \mu$ mole leucovorin with an accuracy of about $\pm 10 \%$. Results are expressed in terms of $\mathbf{m} \mu \mathrm{M}$-leucovorin.

Microbiological assay of 'Lactobacillus casei factor'. The preparation of material was carried out as for the citrovorum factor assay. The assay with Lactobacillus casei (ATCC 7469) was performed by the method of Nimmo-Smith, Lascelles \& Woods (1948), slightly modified in that a final volume of $2.0 \mathrm{ml}$./tube was found adequate to obtain reproducible results. As in other growth experiments, extent of growth was estimated with an EEL photoelectric colorimeter (Evans Electroselenium Ltd., Harlow, Essex) using $\mathbf{0 . 2 5}$ in. tubes and a neutral density filter.

Microbiological assay of factors active for Streptococcus faecalis $R$. The material for assay was prepared as above. The test organism was $S$. faecalis Rogers (ATCC 8043) maintained as described by Lascelles \& Woods (1954); the assay procedure was that of Lascelles \& Woods (unpublished). Medium $G$ of Lascelles \& Woods (1954), modified by the exclusion of thymine and pteroylglutamic acid, and the addition of pyridoxine ( $1 \mathrm{mg}$./l.) was the basal medium. The latter, together with the test solution or pteroylglutamic acid as standard, was distributed to $1.9 \mathrm{ml}$. final volume in hard glass tubes $(125 \times 16 \mathrm{~mm}$.), and autoclaved for $7 \mathrm{~min}$. at $10 \mathrm{lb}$./sq.in. The inoculum was derived from a fresh stab culture in medium $B_{1}$ which was subcultured into medium $B_{2}$ (Nimmo-Smith et al. 1948) and incubated $18 \mathrm{hr}$. at $37^{\circ}$. This culture was diluted fifty-fold, and each tube inoculated with $0.1 \mathrm{ml}$. (about $10^{7}$ organisms). Incubation was for $20-24 \mathrm{hr}$. at $37^{\circ}$ in air.

Standards containing pteroylglutamic acid $\left(1\right.$ to $\left.16 \times 10^{-10} \mathrm{M}\right)$ were set up in each assay; the content of factors active for Streptococcus faecalis $\mathbf{R}$ is recorded as $m \mu \mathrm{M}$ equivalent pteroylglutamic acid by direct comparison of the response obtained at two concentrations with the dose-response curve given by synthetic pteroylglutamic acid.

The response curve for samples approximated to that for pteroylglutamic acid (PtG) at lower concentration (Fig. 2). The deviation at higher levels will be discussed in the text. 
Chemicals. The pteroylglutamic acid was 'Folvite' (Lederle Laboratories, Pearl River, New York, U.S.A.). The source of all other materials, and the preparation and storage of stock solutions, were described by Lascelles et al. (1954).

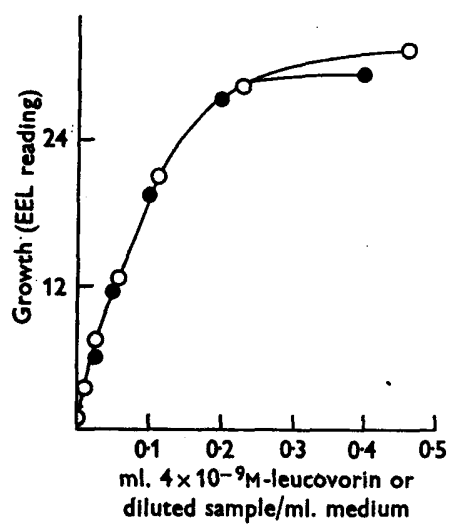

Fig. 1

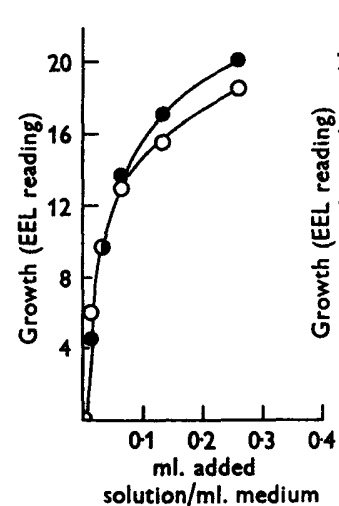

Fig. $2 a$

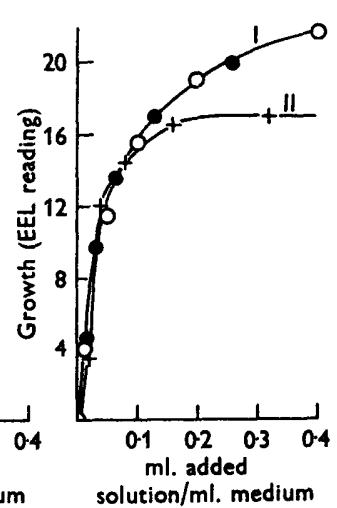

Fig. $2 b$

Fig. 1. Response of Leuconostoc citrovorum to leucovorin (-O) and to a typical sample $(\mathrm{O}-\mathrm{O})$ containing active factor synthesized by suspensions of $L$. mesenteroides P60 variant strain.

Fig. 2a. Response of Streptococcus faecalis $\mathbf{R}$ to pteroylglutamic acid $(\mathrm{O}-\mathrm{O})$ and to a typical sample ( - ) containing active factor synthesized by suspensions of Leuconostoc mesenteroides $\mathbf{P} 60$ variant strain.

Fig. 2b. Response of Streptococcus faecalis $\mathbf{R}$ to $\mathbf{I}, \mathbf{N}^{10}$-formylpteroic acid $(O-O)$ and a typical sample $(-\infty)$ containing active factor synthesized by suspensions of Leuconostoc mesenteroides $\mathbf{P} 60$ variant strain; and II, pteroic acid $(+-+)$. $\mathbf{N}^{10}$-formylpteroic and pteroic acids were added, as $4 \times 10^{-9} \mathrm{M}$ and $4 \times 10^{-8} \mathrm{M}$ solutions respectively diluted from $10^{-6} \mathrm{M}$ solutions in 'boiled control' samples. The sample was added as a 1 in 60 dilution of the incubated system.

\section{RESULTS}

The synthesis of citrovorum factor by suspensions of Leuconostoc mesenteroides P60 variant strain

Lascelles \& Woods (1954) showed that during the synthesis of serine from glycine and formate by suspensions of Streptococcus faecalis $\mathbf{R}$, there was a concurrent formation of a factor or factors active for the growth of $L$. citrovorum. A similar appearance of this factor attended the production of serine by suspensions of $L$. mesenteroides $\mathbf{P} 60$; glucose, formate and $p$-aminobenzoic acid were essential substrates (Table 1; Figs. 3-5).

The growth of Leuconostoc mesenteroides P60 in the absence of serine and leucovorin is dependent on the enrichment of the atmosphere with $\mathrm{CO}_{2}$ (Lascelles et al. 1954). No effect of such a gas phase on the synthesis of serine by suspensions of $L$. mesenteroides $\mathbf{P} 60$ variant stain were detected, but the increase in citrovorum factor synthesis was considerable, varying from 5- to 20-fold in a number of experiments.

A maximum effect of $\mathrm{CO}_{2}$ was observed at a partial pressure of $20 \%$ atmospheric (Fig. 6). The enhancement of citrovorum factor synthesis cannot be ascribed to a 
Table 1. Synthesis of factors with folic acid activity by suspensions of Leuconostoc mesenteroides P60 variant strain

Incubation was in the basal solution $D$ (with omissions as below) for $24 \mathrm{hr}$.

\begin{tabular}{|c|c|c|c|}
\hline Omissions from basal solution & Gas phase & $\begin{array}{l}\text { 'S. faecalis } R \\
\text { factor' found } \\
\text { (m } \mu \mathrm{M})\end{array}$ & $\begin{array}{l}\text { 'Citrovorum } \\
\text { factor' found } \\
\text { (m } \mu \mathrm{M})\end{array}$ \\
\hline $\begin{array}{l}\text { None } \\
\text { None (heated control) } \\
\text { Glycine } \\
\text { Pyridoxal } \\
\text { Formate } \\
\text { p-AB } \\
\text { Glucose }\end{array}$ & $\begin{array}{c}20 \%(v / v) \mathrm{CO}_{2} \\
+ \\
80 \%(v / v) \mathrm{N}_{2}\end{array}$ & $\begin{array}{r}350 \\
5 \\
\mathbf{3 0 0} \\
\mathbf{3 5 0} \\
\mathbf{2 0} \\
\mathbf{5} \\
\mathbf{3 0}\end{array}$ & $\begin{array}{r}40 \\
1 \\
40 \\
40 \\
3 \\
1 \\
3\end{array}$ \\
\hline None & $\mathbf{N}_{2}$ & $\mathbf{3 5 0}$ & 4 \\
\hline
\end{tabular}

change in the $\mathrm{pH}$ value of the medium (Table 2). Over a range of initial $\mathrm{pH}$ values from $7 \cdot 1$ to $6 \cdot 1$ the decrease in $\mathrm{pH}$ during incubation in $\mathrm{N}_{2}$ was about $0 \cdot 3-0 \cdot 6$ of a unit. This increased to between 0.5 and 0.8 of a $\mathrm{pH}$ unit when incubation was in $20 \%(\mathrm{v} / \mathrm{v}) \mathrm{CO}_{2}+80 \%(\mathrm{v} / \mathrm{v}) \mathrm{N}_{2}$. Though citrovorum factor formation was apparently increased by an acid environment, the synthesis in $\mathbf{N}_{2}$ at initial pH 6.1 was only about $40 \%$ of that in $20 \%(\mathrm{v} / \mathrm{v}) \mathrm{CO}_{2}+80 \%(\mathrm{v} / \mathrm{v}) \mathrm{N}_{2}$ at initial $\mathrm{pH} 7 \cdot 1$. The increased synthesis in more acid media cannot account for the carbon dioxide effect.

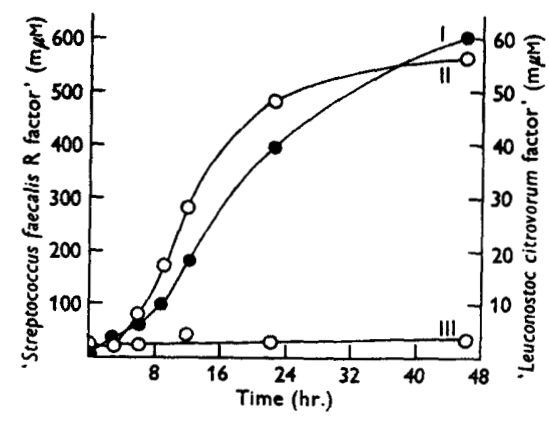

Fig. 3

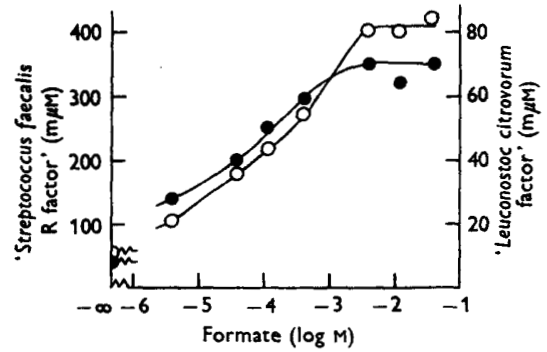

Fig. 4

Fig. 3. Rates of synthesis by suspensions of the variant strain of 'citrovorum factor' $\left(O_{-O}\right)$ and 'Streptococcus faecalis $\mathbf{R}$ factor' (O-O) in solution $D$. Curves I and III were obtained by incubation in $\mathrm{N}_{2}$; curve $I I$ by incubation in $20 \% \mathrm{CO}_{2}$ in $\mathrm{N}_{2}$

Fig. 4. Effect of formate concentration on the synthesis of 'citrovorum factor' $(\mathrm{O}-\mathrm{O})$ in $20 \% \mathrm{CO}_{2}$ in $\mathrm{N}_{2}$, and 'Streptococcus faecalis $\mathrm{R}$ factor' $(--)$ ) in $\mathrm{N}_{2}$ by suspensions of the variant strain. Incubation for $24 \mathrm{hr}$. in solution $D$ omitting pyridoxal and glycine.

It seemed possible that $\mathrm{CO}_{2}$ might be involved in the formation of the glutamic acid moiety of citrovorum factor. Both DL- and L-glutamic acid were inactive however, over the concentration range $10^{-1}$ to $10^{-4} \mathrm{M}$.

The glucose concentration is also a critical factor in the production of citrovorum factor; peak synthesis occurred at c. $10^{-2} \mathrm{M}$-glucose. 
Table 2. Effects of $\mathrm{pH}$ value and $\mathrm{CO}_{2}$ on synthesis of folic acid group factors by suspensions of Leuconostoc mesenteroides $P 60$ variant strain

Suspensions incubated in solution $D$ minus glycine and pyridoxal for $24 \mathrm{hr}$.

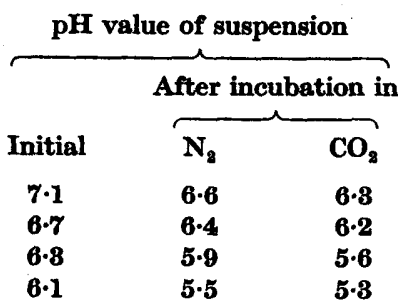

'Citrovorum factor' (m $\mu \mathrm{M})$ found.

After incubation in

$\begin{array}{rr}\mathrm{N}_{2} & \mathrm{CO}_{2} \\ 4.5 & 33.0 \\ 7 \cdot 0 & 33.0 \\ 10.5 & 35.5 \\ 13.5 & 31.5\end{array}$

'S. faecalis $\mathbf{R}$ factor' ( $\mathrm{m} \mu \mathrm{M}$ ) found. After incubation in $\mathbf{N}_{2}$ 380 125 75

As for maximum serine synthesis, $5 \times 10^{-3} \mathrm{M}$-formate was the minimum concentration which gave an optimum yield of citrovorum factor (Fig. 4). However, production of the latter increased with $p$-aminobenzoic acid concentration up to $1^{-5} \mathrm{M}$, a hundred times that required for most rapid formation of serine (Fig. 5). Pteroylglutamic acid was not converted to citrovorum factor by suspensions.

The ability of the organisms to synthesize citrovorum factor varied with their physiological age. For best activity the organisms for suspension were harvested after 10-11 hr. as previously described (Cross, 1960).

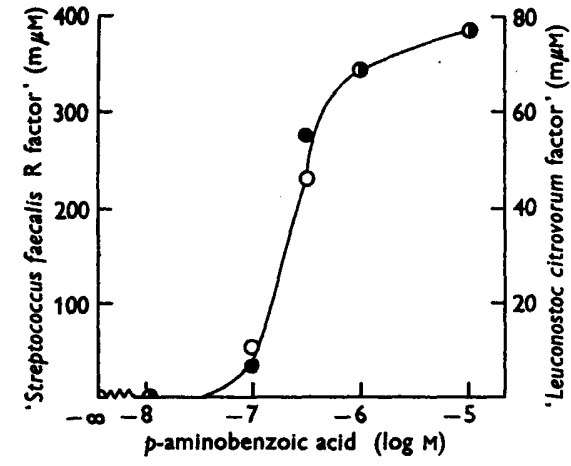

Fig. 5

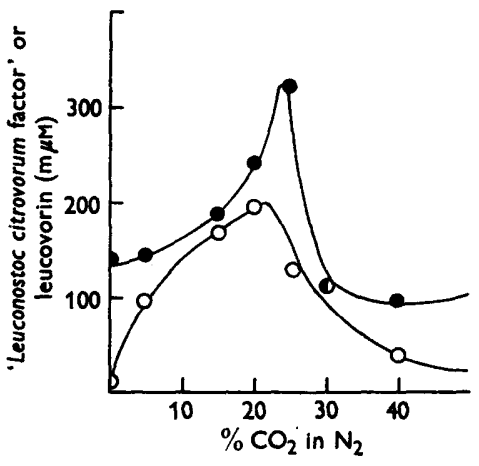

Fig. 6

Fig. 5. Effect of $p$-aminobenzoic acid concentration on the synthesis of 'citrovorum factor' (-) (incubation in $20 \% \mathrm{CO}_{2}$ in $\mathrm{N}_{2}$ ) and 'Streptococcus faecalis $\mathrm{R}$ factor' $(\mathrm{O}-\mathrm{O})$ (incubation in $\mathrm{N}_{2}$ ) by suspensions of the variant strain incubated in solution $D$ omitting glycine and pyridoxal, for $24 \mathrm{hr}$.

Fig. 6. Effect of partial pressure of $\mathrm{CO}_{2}$ on the destruction of leucovorin and the synthesis of 'citrovorum factor' by the variant strain. Leucovorin remaining $(-0)$ from an initial concentration of $1000 \mathrm{~m} \mu \mathrm{M}$ after incubation with organisms suspended in phosphate buffer and $10^{-2} \mathrm{M}$-glucose; 'citrovorum factor' synthesized $(\mathrm{O}-\mathrm{O})$ in solution $D$ omitting glycine and pyridoxal. Incubation was for $24 \mathrm{hr}$. at $37^{\circ}$ in both cases.

The synthesis of factors active for Streptococcus faecalis $R$ by suspensions of Leuconostoc mesenteroides $P 60$, variant strain

The supernatant fluids from suspensions of the variant strain in solution $D$ incubated in $\mathrm{N}_{2}$ (which contained serine and a little citrovorum factor) were also active in supporting the growth of $S$. faecalis $R$, and in replacing pteroylglutamic acid 
The concentration of active factor in terms of equivalent pteroylglutamic acid was about one hundred times that of the citrovorum factor present, in terms of equivalent leucovorin (Fig. 3). Since it is likely that the (-)-L-isomer of leucovorin (the active isomer) has activity for $S$. faecalis $\mathbf{R}$ equal to that of pteroylglutamic acid (Broquist et al. 1952; Cosulich, Smith \& Broquist, 1952), and the citrovorum factor synthesized by $L$. mesenteroides $\mathbf{P} 60$ would appear to be at least closely related to leucovorin, it seems that this activity for $\boldsymbol{S}$. faecalis $\mathbf{R}$ cannot be ascribed to the small quantity of citrovorum factor present. Furthermore, suspensions incubated in $20 \%$ $\mathrm{CO}_{2}$ yielded the same, or in some experiments a lower, concentration of ' $\mathrm{S}$. faecalis $R$ factor' than those incubated in $\mathrm{N}_{2}$, in contrast to the greater activity of the former supernatant fluids for $L$. citrovorum (Table 1 ).

In other respects the requirements for 'Streptococcus faecalis $\mathbf{R}$ factor' synthesis are identical to those for formation of citrovorum factor (Table 1; Figs. 3-5). Glucose, $p$-aminobenzoic acid and formate were essential components of the system; omission of glycine and pyridoxal from solution $D$ had no significant effect. The production of ' $S$. faecalis $\mathbf{R}$ factor', like that of citrovorum factor, reaches a maximum at $10^{-5} \mathrm{M}$ - $p$-aminobenzoic acid and $5 \times 10^{-3} \mathrm{M}$-formate. The synthesis, however, increases with glucose concentration up to $10^{-1} \mathrm{M}$; there is no peak activity at a lower concentration as with citrovorum factor.

Neither after incubation in $\mathrm{CO}_{2}$ nor in $\mathrm{N}_{2}$ was any activity for Lactobacillus casei demonstrable beyond that which could be ascribed to citrovorum factor in the samples. The response of Streptococcus faecalis $\mathbf{R}$ to the preparations was not due, therefore, to the presence of pteroylglutamic acid, which also supports growth of L. casei (Broquist et al. 1952).

The response of Streptococcus faecalis $\mathbf{R}$ to the supernatant fluid from a suspension of Leuconostoc mesenteroides $\mathbf{P} 60$ variant strain in glucose, phosphate buffer, formate and $p$-aminobenzoic acid incubated in $\mathrm{N}_{2}$ was compared to the response to pteroic acid and rhizopterin (Fig. $2 b$ ). The pteroic acid and rhizopterin added as standards were diluted from $10^{-6} \mathrm{M}$ solutions in supernatant fluids from 'boiled control' suspensions of the variant strain in the above medium. The dose/response curve for the active samples much more nearly approached that for rhizopterin than that for pteroic acid.

\section{The activity of suspensions of Leuconostoc mesenteroides $P 60$ previously incubated in glucose}

After pre-incubation, Leuconostoc mesenteroides $P 60$ variant strain incubated in solution $D$ did not yield significant quantities of citrovorum factor whether $\mathrm{CO}_{2}$ was present or not; however, their ability to synthesize 'Streptococcus faecalis $\mathbf{R}$ factor' was not impaired (Table 3).

\section{The response of Leuconostoc mesenteroides $P 60$ to factors formed by} suspensions of the variant strain

It was not possible to draw any conclusions from direct tests of the ability of samples to support the growth of Leuconostoc mesenteroides P60 since these samples contained relatively high concentrations of $p$-aminobenzoic acid which is the most potent member of the folic acid group known for this organism. However, the relative efficiencies of samples in antagonizing sulphathiazole-inhibition were as 
Table 3. Synthesis of folic acid group factors by suspensions of Leuconostoc mesenteroides $P 60$ variant strain

Organisms incubated in basal solution $D$ for $24 \mathrm{hr}$. after pre-incubation where indicated.

\begin{tabular}{|c|c|c|c|c|}
\hline \multirow[b]{2}{*}{ Gas phase } & \multicolumn{2}{|c|}{$\begin{array}{l}\text { 'Citrovorum factor' (m } \mu \mathrm{M}) \\
\text { found when organisms }\end{array}$} & \multicolumn{2}{|c|}{$\begin{array}{l}\text { 'S. faecalis R factor' (m } \mu \mathrm{M}) \\
\text { found when organisms }\end{array}$} \\
\hline & Pre-incubated & Normal & Pre-incubated & Normal \\
\hline $\begin{array}{l}\mathrm{N}_{2} \\
20 \%(\mathrm{v} / \mathrm{v}) \mathrm{CO}_{2}+ \\
\quad 80 \%(\mathrm{v} / \mathrm{v}) \mathrm{N}_{2}\end{array}$ & $\begin{array}{l}0 \cdot 2 \\
0 \cdot 2\end{array}$ & $\begin{array}{l}0 \cdot 2 \\
8 \cdot 2\end{array}$ & $\begin{array}{l}\mathbf{5 5 0} \\
\mathbf{5 5 0}\end{array}$ & $\begin{array}{l}550 \\
550\end{array}$ \\
\hline
\end{tabular}

might be expected if a rhizopterin-like compound were formed by incubating suspensions in $\mathbf{N}_{2}$, together with a leucovorin-like compound when incubation was in an atmosphere enriched with $\mathrm{CO}_{2}$ (Table 4). Sulphathiazole inhibited growth of the parent strain in the presence of a sample showing activity for Streptococcus faecalis $\mathbf{R}$ equivalent to $2 \cdot 2 \times 10^{-8} \mathrm{M}$-pteroylglutamic acid; but did not inhibit, even at $10^{-3} \mathrm{M}$-sulphathiazole, a sample (from incubation in $20 \% \mathrm{CO}_{2}$ ) which showed also citrovorum factor equivalent to $4 \cdot 2 \times 10^{-9} \mathrm{M}$-leucovorin. Rhizopterin is inactive for the growth of L. mesenteroides P60 (Lascelles et al. 1954).

Table 4. Antagonism of sulphathiazole-inhibition of the groroth of Leuconostoc mesenteroides $P 60$ by factors of the folic acid group

Leuconostoc mesenteroides $\mathbf{P} 60$ was grown in medium $L$ supplemented with $5 \times 10^{-4} \mathrm{M}$ glycine, $10^{-8} \mathrm{M}-\mathrm{DL}$-serine and $2 \times 10^{-7} \mathrm{M}$-pyridoxal in air. The added samples were derived from incubated suspensions of the variant strain prepared for assay in the usual way.

Sample $\mathbf{A}$ (from incubation in $\mathbf{N}_{2}$ ) contains 'Streptococcus faecalis $\mathbf{R}$ factor' equivalent to $2.2 \times 10^{-8} \mathrm{M}-\mathrm{PtG}$ and 'citrovorum factor' equivalent to $0.1 \times 10^{-9} \mathrm{M}$-leucovorin.

Sample $\mathrm{B}$ (from incubation in $\mathrm{CO}_{2}$ ) contains ' $S$. faecalis $\mathbf{R}$ factor' equivalent to $1.8 \times 10^{-8} \mathrm{M}-\mathrm{PtG}$ and 'citrovorum factor' equivalent to $4.2 \times 10^{-9} \mathrm{M}$-leucovorin.

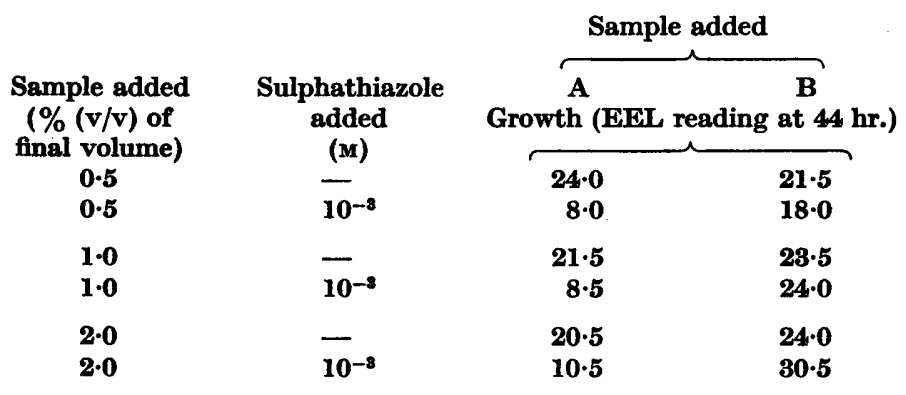

The inhibition of the synthetic ability of suspensions of the variant strain by sulphathiazole

Like the synthesis of serine (Cross, 1960), the synthesis of citrovorum factor and 'Streptococcus faecalis $\mathbf{R}$ factor' by suspensions of Leuconostoc mesenteroides $\mathbf{P} 60$ variant strain was inhibited by sulphathiazole; each inhibition was competitively antagonized by $p$-aminobenzoic acid (Table 5). ' $S$. faecalis $\mathbf{R}$ factor' formed by suspensions of $L$. mesenteroides $\mathbf{P} 60$ variant strain did not annul sulphathiazoleinhibition of the growth of $L$. mesenteroides $P 60$ in a non-competitive manner. Yet 
the Streptococcus factor is the product of a sulphathiazole-inhibited reaction in L. mesenteroides P60. The simplest interpretation of these facts is that the Streptococcus factor cannot support the growth of $L$. mesenteroides P60. This is again in accordance with indications that the Streptococcus factor is a rhizopterin-like compound.

Table 5. Inhibition by sulphathiazole of the synthesis of folic acid group factors by suspensions of Leuconostoc mesenteroides $P 60$ variant strain

Organisms incubated in solution $D$ minus $p$-AB for $24 \mathrm{hr}$.

$\begin{array}{ccc}\begin{array}{c}\text { p-AB added } \\ (\mathrm{M})\end{array} & \begin{array}{c}\text { Sulphathiazole } / p \text {-AB ratio required } \\ \text { for } 50 \% \text { inhibition of synthesis of }\end{array} \\ & \begin{array}{c}\text { Citrovorum } \\ \text { factor' }\end{array} & \begin{array}{c}S \text {. faecalis } \\ \mathbf{R} \text { factor' }\end{array} \\ 4 \times 10^{-7} & 2.0 & 2.0 \\ 10^{-6} & 1.6 & 1.5 \\ 4 \times 10^{-6} & 1.6 & 1.3 \\ 4 \times 10^{-5} & 1.0 & 1.3\end{array}$

The inactivation of leucovorin by suspensions of Leuconostoc mesenteroides $P 60$ variant strain

The decrease of activity of leucovorin (citrovorum factor) added to suspensions of Leuconostoc mesenteroides $\mathbf{P} 60$ variant strain was rapid. Carbon dioxide partially prevented the inactivation of leucovorin during incubation, maximum inhibition occurring in atmospheres containing $20-25 \% \mathrm{CO}_{2}$. This is a partial pressure which approximates to that required for maximum de novo formation of citrovorum factor (Fig. 6). Of the leucovorin originally present only $7 \%$ remained after incubation with $L$. mesenteroides $P 60$ variant strain in $\mathrm{N}_{2}$ whilst $16 \%$ remained in $25 \%(\mathrm{v} / \mathrm{v})$ $\mathrm{CO}_{2}+75 \%(\mathrm{v} / \mathrm{v}) \mathrm{N}_{2}$. Leucovorin activity was not lost by incubation at $10^{-6} \mathrm{M}$ with suspensions inactivated by heating at the outset of the experiment, nor in the course of preparation of samples for assay.

The inactivation of leucovorin was considerable even in the absence of glucose, but was greatly accelerated in its presence. A critical increase in this enhancement of the degradation occurred at about $10^{-2} \mathrm{M}$-glucose; this might explain the diminution in apparent citrovorum factor synthesis with increasing glucose concentration which occurred at this concentration of glucose, resulting in the peak already described.

\section{The replacement of $\mathrm{CO}_{2}$ by ascorlic acid}

Carbon dioxide has the dual capacity of stimulating serine synthesis (Lascelles et al. 1954; Cross, 1960) and of preventing leucovorin inactivation by Leuconostoc mesenteroides $\mathbf{P} 60$. Any hypothesis about a relationship between these two activities would be supported if another compound which produced one of the phenomena also produced the other. With such a possibility in view tests were carried out with L-ascorbic acid which has been reported to increase citrovorum factor production by suspensions and extracts of Streptococcus faecalis $\mathbf{R}$ (Broquist et al. 1953; Nichol, 1954). When examined L-ascorbic acid $\left(10^{-2} \mathrm{M}\right)$ was found to stimulate synthesis of 
citrovorum factor from formate and $p$-aminobenzoic acid and partially prevented inactivation of $10^{-8} \mathrm{M}$-leucovorin by suspensions of $L$. mesenteroides $\mathrm{P} 60$ variant strain, though the effect was not so marked as that produced by $\mathrm{CO}_{2}$ (Table 6). It was also found that $(a)$ recovery of $5 \times 10^{-8} \mathrm{M}$-leucovorin from 'boiled controls' was almost complete in the presence or absence of ascorbic acid, and that (b) L-ascorbic acid had little effect when it was present only during the preparation of the samples for assay after incubation.

Table 6. Effect of ascorbic acid and $\mathrm{CO}_{2}$ on the synthesis and degradation of 'citrovorum factor' by suspensions of Leuconostoc mesenteroides P60 variant strain

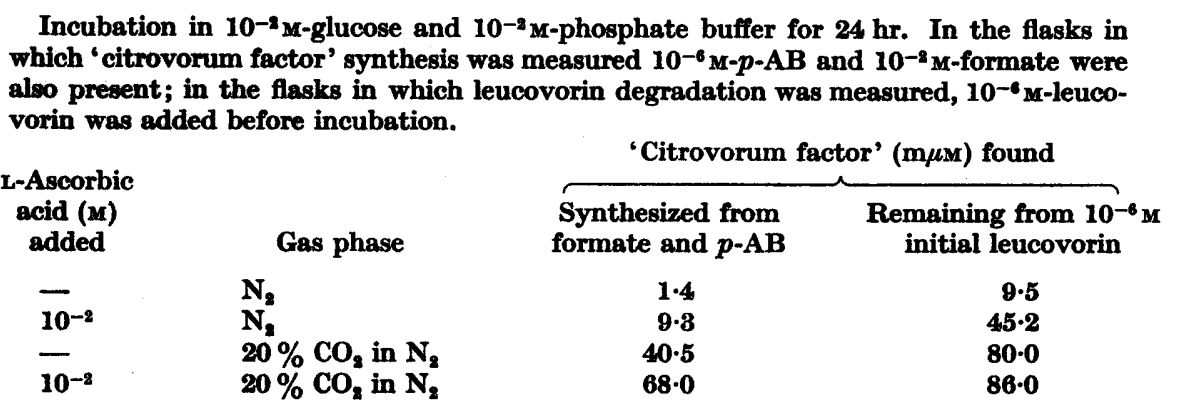

Ascorbic acid partially replaced $\mathrm{CO}_{2}$ for the growth of Leuconostoc mesenteroides $\mathbf{P} 60$ in the absence of serine, but growth only reached one-third of that attained in $5 \%(\mathrm{v} / \mathrm{v}) \mathrm{CO}_{2}+95 \%(\mathrm{v} / \mathrm{v}) \mathrm{N}_{2}$. The activity of L-ascorbic acid was confirmed by its stimulatory action when the organism was grown in the absence of serine with suboptimal concentrations of leucovorin or $\mathrm{CO}_{2}$ (Table 7). When medium $L$ was supplemented with $\mathbf{1 0}^{-3} \mathrm{M}$-DL-serine no such stimulation occurred.

Table 7. Effect of ascorbic acid on the growth of Leuconostoc mesenteroides $\boldsymbol{P} 60$

Growth in medium $L$ supplemented with $5 \times 10^{-4} \mathrm{M}$-glycine, $2 \times 10^{-7} \mathrm{M}-$ pyridoxal and $10^{-1}-\mathrm{p}-\mathrm{AB}$; and with and without $5 \times 10^{-8} \mathrm{M}-\mathrm{L}$-ascorbic acid.

Additions to basal medium

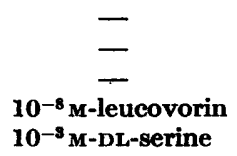

$$
\text { Gas phase }
$$$$
\mathbf{N}_{2}
$$$$
0.5 \% \mathrm{CO}_{2} \text { in } \mathrm{N}_{2}
$$$$
5 \cdot 0 \% \mathrm{CO}_{8} \text { in } \mathrm{N}_{2}
$$$$
\mathbf{N}_{2}
$$

Growth (EEL reading in $44 \mathrm{hr}$.)

\begin{tabular}{|c|c|}
\hline $\begin{array}{l}\text { Without } \\
\text { ascorbate }\end{array}$ & $\begin{array}{c}\text { With } \\
\text { ascorbate }\end{array}$ \\
\hline $1 \cdot 0$ & $7 \cdot 5$ \\
\hline 6.5 & $18 \cdot 5$ \\
\hline $20 \cdot 0$ & $22 \cdot 5$ \\
\hline 14.5 & 22.5 \\
\hline $22 \cdot 5$ & $24 \cdot 0$ \\
\hline
\end{tabular}

\section{DISCUSSION}

When incubated with $p$-aminobenzoic acid and formate suspensions of a variant strain of Leuconostoc mesenteroides $\mathbf{P} 60$ form two factors having folic acid activity. $p$-Aminobenzoic acid is also required for the synthesis of serine (Cross, 1960), and these factors are formed concurrently with serine when glycine and pyridoxal are also provided. Though some form of folic acid is clearly required for serine synthesis 
by this organism, the present experiments provide no evidence of the identity of the final coenzyme form (CoF).

The two factors formed in the suspensions have been tentatively identified as rhizopterin and leucovorin on the basis of their activities for various micro-organisms. It is unlikely that either of these factors is even an intermediate in the synthesis of CoF from $p$-aminobenzoic acid. Rhizopterin is transformed to citrovorum factor by suspensions of Streptococcus faecalis $\mathbf{R}$ (Hendlin, Koditschek \& Soars, 1953), but it does not support the growth of Leuconostoc mesenteroides P60. It is improbable that this inactivity is due to the impermeability of the cells to the factor, since leucovorin and tetrahydropteroyl-glutamic acid, both containing a pteridine residue, albeit reduced, support growth of the organism (Lascelles et al. 1954; Cross, 1956). Leucovorin, likewise, is inactive for a number of micro-organisms, and probably does not mediate in the main pathway to CoF (Woods, 1954). Nevertheless, it may be a sufficiently close by-product of CoF metabolism for its formation to give a measure of the synthesis of the coenzyme.

An inverse quantitative relationship exists between the requirements for leucovorin and glycine for the growth of Leuconostoc mesenteroides $\mathbf{P} 60$ in the absence of serine, just as it does between $\mathrm{CO}_{2}$ and glycine (Lascelles et al. 1954). Leucovorin will also satisfy the requirement for $\mathrm{CO}_{2}$ of suspensions of the pre-incubated cells synthesizing serine (Cross, 1960). One interpretation of these observations is that $\mathrm{CO}_{2}$ maintains a concentration of $\mathrm{CoF}$ sufficient for the synthesis of serine. In support of this view it is now found that the formation of citrovorum factor in suspensions of the variant strain of $L$. mesenteroides $\mathrm{P} 60$ is enhanced by $\mathrm{CO}_{2}$. If $\mathrm{CO}_{2}$ is essential for the formation of $\mathrm{CoF}$, then $\mathrm{CO}_{2}$ should be necessary for the synthesis of serine. But optimum concentrations of serine are formed by suspensions of the freshly harvested variant strain in an atmosphere of $\mathrm{N}_{2}$ (Cross, 1960). Again, unless $p$-aminobenzoic acid has some function in bacterial metabolism apart from the synthesis of CoF, $L$. mesenteroides P60 should fail to grow in atmospheres devoid of $\mathrm{CO}_{2}$ unless the requirement for $p$-aminobenzoic acid were also eliminated. However, growth of the organism in the presence of serine occurs only when $p$-aminobenzoic acid is supplied, and yet it proceeds in $\mathrm{N}_{2}$ (Lascelles et al. 1954).

Carbon dioxide partially inhibits the inactivation of leucovorin by suspensions of the variant strain of Leuconostoc mesenteroides $P 60$. If this inactivation reflects a loss of $\mathrm{CoF}$, then $\mathrm{CO}_{2}$ may exert its influence on $\mathrm{CoF}$ concentration, and therefore on serine synthesis, by inhibiting degradation of the coenzyme. It is assumed that the CoF concentration is sufficiently high, even in the absence of $\mathrm{CO}_{2}$, for the synthesis of serine by freshly harvested suspensions, and for the requirements of the organism growing in the presence of serine. On the other hand, it is insufficient, in the absence of $\mathrm{CO}_{2}$, for the synthesis of serine either by growing organisms or by suspensions of organisms previously incubated in phosphate-buffered glucose. In fact no citrovorum factor formation has been detected in suspensions of the preincubated organisms, although serine is synthesized under these conditions. It may be that the assay is not sensitive enough to detect small quantities of citrovorum factor consonant with serine synthesis. The hypothesis that the parts played by $\mathrm{CO}_{2}$, in serine synthesis, in citrovorum factor synthesis and in leucovorin degradation are closely related in $L$. mesenteroides $\mathbf{P 6 0}$, receives some support from the fact that ascorbic acid can partially replace $\mathrm{CO}_{2}$ in each of these roles. 
I wish to thank Professor D. D. Woods, F.R.S., and Dr June Lascelles for their many suggestions and helpful criticism. The work was carried out during the tenure of a Guinness Research Fellowship in Microbiological Biochemistry.

\section{REFERENCES}

Broquist, H. P., Brockman, J. A., Fahrenbach, M. J., Stokstad, E. L. R. \& Jukes, T. H. (1952). Comparative biological activity of leucovorin and pteroylglutamic acid. $J$. Nutr. 47, 93.

Broquist, H. P., Kohler, A. R., Hutchison, D. J. \& Burchenal, J. H. (1953). Studies on the enzymatic formation of citrovorum factor by Streptococcus faecalis. J. biol. Chem. 202, 59.

Cosulich, D. B., Smith, J. M. \& Broquist, H. P. (1952). Diastereoisomers of leucovorin. J. Amer. chem. Soc. 74, 4215.

Cross, M. J. (1956). The Metabolism of Serine by Micro-Organisms. D.Phil. Thesis: University of Oxford.

Cross, M. J. (1960). The synthesis of serine by Leuconostoc mesenteroides P60. J. gen. Microbiol. 23, 105.

Hendin, D., KoditscheK, L. K. \& Soars, M. H. (1953). Investigations of the biosynthesis of citrovorum factor by lactic acid bacteria. J. Bact. 65, 466 .

Lascelles, J., Cross, M. J. \& Woods, D. D. (1954). The folic acid and serine nutrition of Leuconostoc mesenteroides P60 (Streptococcus equinus P60). J. gen. Microbiol. 10, 267.

Lascelnes, J. \& Woods, D. D. (1952). The synthesis of 'folic acid' by Bacterium coli and Staphylococcus aureus and its inhibition by sulphonamides. Brit. J. exp. Path. 33, 288.

LASCELleS, J. \& Woods, D. D. (1954). The synthesis of serine and Leuconostoc citrovorum factor by cell suspensions of Streptococcus faecalis $R$. Biochem. J. 58, 486.

Nichol, C.A. (1954). Studies of the mechanism of resistance to folic acid analogues in a strain of Streptococcus faecalis. J. biol. Chem. 207, 725.

Nimmo-Smith, R. H., Lascelles, J. \& Woods, D. D. (1948). The synthesis of 'folic aid' by Streptobacterium plantarum and its inhibition by sulphonamides. Brit. J. exp. Path. 29, 264.

Woods, D. D., (1954). In Chemistry and Biology of Pteridines, pp. 220-36, 300. Ed. G. E. W. Wolstenholme \& M. P. Cameron. London: J. and A. Churchill. 